\title{
Multiple-element line segment precues: Orientation and location effects on attention
}

\author{
GARVIN CHASTAIN \\ Boise State University, Boise, Idaho
}

\begin{abstract}
Three experiments were conducted to examine the hypothesis that a uniquely oriented line segment located at the end of the directional flow produced by the alignment of the long axes of identically oriented background segments will not be detected as rapidly as when the segment appears at locations within the flow. The hypothesis was supported with response time measured in Experiment 1. A location-cuing task was used in the last two experiments, with the unique segment becoming a precue to indicate the location of an upcoming target character; accuracy was the dependent measure. Poorer detection of the unique segment at end-of-flow locations was shown not to be due to a local configuration effect produced by the uniquely oriented segment in conjunction with the segment on either side. The time course of attentional development with multiple-segment precue displays was comparable to that with an arrow at fixation as the precue, and slower than that with a line segment appearing alone.
\end{abstract}

The present studies were conducted to explore the visibility of a single unique slanted line segment when it appears in different spatial locations in conjunction with other segments that share an orientation with each other. The directional flow produced by these other segments may make the unique segment more difficult to detect at some locations than at others.

If a line segment appears among a number of others that differ from it (but not from each other) in orientation by $45^{\circ}$ or more, the unique segment is detected through parallel processing in such a way that it seems to "pop out" from its background (Nothdurft, 1991; Treisman, 1986). Indeed, Treisman (1986) found that adding background items with identical orientations does not lessen the pop-out effect, as judged by the speed with which the unique item elicits a response (see also Sagi \& Julesz, 1985; Treisman \& Gormican, 1988).

Although this pop-out can be detected through parallel processing, it may not draw attention automatically. Attention can be summoned automatically by a single abrupt luminance increment, appearing as a small shape in an otherwise empty visual field (Yantis \& Jonides, 1984, 1990). In fact, Jonides and Yantis (1988) argued that a single-element abrupt visual onset is unique in its effectiveness in capturing attention (see also Remington, Johnston, \& Yantis, 1992). Attention effects often have been studied by presenting a single element near the location of a target character that appears afterward among a circular array of similar characters (Cheal \& Lyon, 1989; Lyon, 1990).

I would like to thank the editor, MaryLou Cheal, Chip Folk, and Steve Yantis for helpful comments on earlier versions of this article. Correspondence should be sent to G. Chastain, Department of Psychology, Boise State University, Boise, ID 83725 (e-mail: rpschast@ idbsu.idbsu.edu).
The same procedure could be used to study the effects of other types of cues for precuing a location-specifically, a line segment appearing among others of a single, different orientation. That is, the unique line segment could be used to precue the location of a target character in a circular array of characters. Because a line segment has an orientation, comparisons can be made to determine whether such a segment appearing as part of a multipleelement display containing other segments of a different orientation functions as a precue equally well at all locations equidistant from fixation. With the segment appearing as part of a multiple-element display, the degree and direction of difference in orientation between this unique and the other (background) line segments could be important. Wolfe, Friedman-Hill, Stewart, and O'Connell (1992) found parallel processing with a unique line segment that was slanted $20^{\circ}$ right of vertical among background line segments that all were vertical. However, Treisman (1986) found that the converse is not the case; a unique vertical line segment is not found through parallel processing if it appears among background line segments that all are identically slanted (see especially Treisman \& Gormican, 1988).

Moreover, line segments, all but one of which are identically oriented, should produce a global directional flow (Hel-Or \& Zucker, 1989). A line whose orientation is consistent with the directional flow often is difficult to detect, although a line whose orientation contrasts with it usually is easily seen (Moraglia, 1989; Nothdurft, 1991). However, if the array of line segments is fairly sparse (e.g., eight segments spaced equidistantly around an imaginary circle with a diameter of approximately $9^{\circ}$ ), the unique segment might contrast with the directional flow produced by identical alignment of the long axes of the other segments better at some locations than at others. A uniquely oriented line segment may not be detected as rapidly if it 
is in a location that makes it less salient (e.g., at the end of the directional flow). The unique segment may be less salient when it lies as a boundary at the end of the flow because it merely provides redundant information that the flow has ended. The unique segment therefore would not stand out in the same way as it would if it were located within the flow.

Consider the four arrays in Figure 1. The following might provide an adequate operational definition of "the end of the directional flow": Suppose an imaginary line is drawn perpendicular to the alignment of the long axes of the background segments and is moved in either direction to the most peripheral point on the most eccentric segment while being kept perpendicular to that alignment; the segment containing that point is at the end of the directional flow. Therefore, for Array A in Figure 1, the segment at the end of the directional flow is the unique one at the upper right-although it could have been at the lower left - but not the background segment at the top or direct right, because the unique upper right segment contains the most peripheral point as described above. However, for Array B, the unique segment at the direct right is not at the end of the directional flow, because both the top and upper right background segments contain a point that is more peripheral. It also is true with these arrays that, given that the background segments are parallel, if the line that comprises the unique segment is lengthened to span the array, it will be at the end of the directional flow if the extended line does not intersect any background segment. If it does, the unique segment is not at the end of the directional flow. Accordingly, with a flow of vertical lines, the unique segment falls at

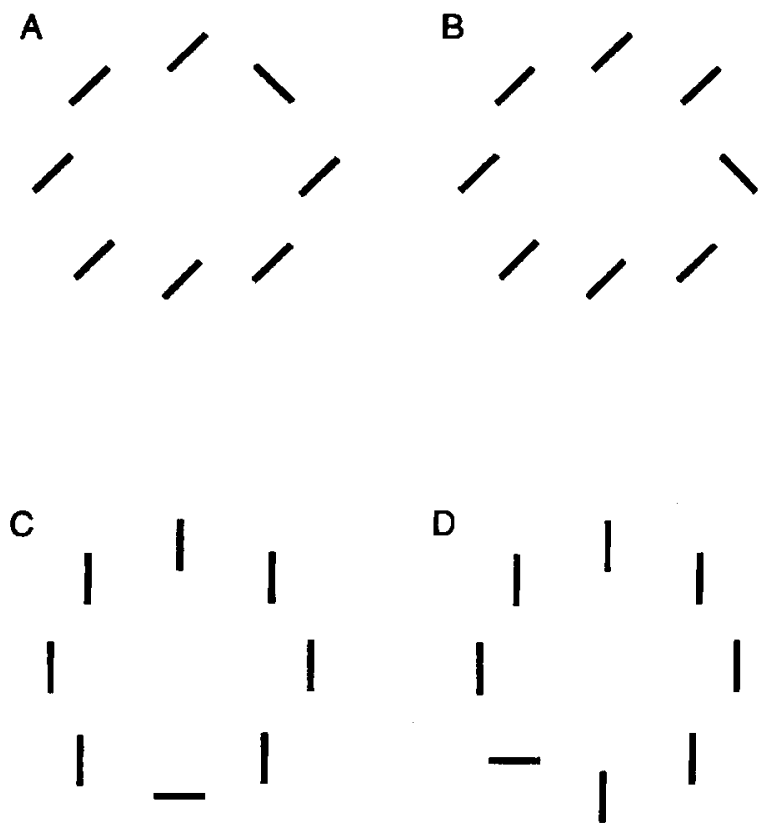

Figure 1. Sample precue arrays, with the unique segment appearing at the end of the directional fow in Arrays $A$ and $C$ but not in Array B or Array D. the end of the directional flow when it is at bottom (Array C) - or top - but not at the lower left (Array D).

Using a unique line segment as a pop-out item that becomes a precue to indicate the location of an upcoming target character to be identified allows the results to be related directly to the location-cuing literature. Also, using accuracy rather than response time as a dependent measure avoids contamination from speed-accuracy tradeoffs and makes clear the time course of attention buildup across a range of precue-target delays. Using such a range of delays will indicate whether the unique line segment in certain orientations is detected more slowly at some locations than at others (or perhaps tends not to be detected at those locations).

The proposition that a unique line segment will not be found as quickly if it is at the end of the directional flow was tested directly in Experiment 1. The task used was a speeded-response task, and the line segments were not used as precues in this experiment. Instead, two, four, or eight line segments appeared equidistant around the circumference of an imaginary circle centered on fixation, and the participant responded as soon as possible with a buttonpress to indicate whether a segment with a prespecified orientation was present or absent. The orientation contrast between the unique and other segments in multiple-element displays always was approximately $90^{\circ}$.

Experiment 2 involved eliminating five of the eight line segments in the circular multiple-element displays, leaving only the unique segment and one segment to each side of it, as a control for local configuration effects that might be misinterpreted as the unique segment being more difficult to detect when it occupies end-of-flow locations with all background segments present. Here the unique segment was used to precue the location of a character to be identified in the target display that followed.

In Experiment 3, line segments were used as precues in either single-element or multiple-element peripheral precue displays, and a condition with an arrow at fixation as a precue was included for comparison. Therefore this experiment allowed determination of the time course of attention build-up with various types of precues in hopes of discovering whether those appearing in the multipleelement precue displays cause attention to develop in a manner similar to that with a single-element peripheral precue, or instead in a manner similar to that with a precue consisting of an arrow at fixation. However, a more central goal of this experiment was to determine the detectability of the unique segment when it appeared at various locations and when it and the background segments that provided directional flow were in various orientations.

\section{EXPERIMENT 1}

In the first experiment, line segments were arranged to produce a single line segment that contrasted in orientation with one, three, or seven others that were identical in their orientation. The number of background segments in the display was varied in order to determine through this experiment whether the unique segment tended to 
pop out of the display by being detected through parallel processing according to the criterion established by Treisman (1977) of reaction time being constant across display sizes. Because the number of segments was varied, it also was possible to infer how many segments needed to be present to produce a directional flow. This test stems from the work of Moraglia (1989) and Nothdurft (1993a). The prediction was that participants would be slower to detect the unique segment in the location that placed it at the end of the directional flow when there were seven background segments in the display. No such flow should be produced with only one background segment, and thus the location effect that should be present with eight segments was not expected. Whether three background segments are enough to produce the effect, and by inference a directional flow, was to be determined.

\section{Method}

Participants. One group of 10 participants served as part of an option to fulfill an outside-of-class activities requirement in an introductory psychology course. Each reported normal or correctedto-normal acuity.

Apparatus. Stimuli were presented on a Zenith ZCM-1490-Z analog display controlled by an IBM PS/2 Model 30 . The decay rate of the P-22 phosphor on the display is to $10 \%$ within $1 \mathrm{msec}$. Distance of the participants' eyes from the display was maintained at approximately $38 \mathrm{~cm}$ by a Gulf \& Western table-mounted chinrest with head restraint.

Stimuli. The target-present display contained one, three, or seven identically oriented line segments (all forward slashes), and one that was different from those (a backslash), across eight possible locations, $4.25^{\circ}$ from fixation. The target-absent display contained all backslashes. There was one possible location every $45^{\circ}$ (over $3^{\circ}$ of visual angle apart), equally spaced around the circumference of an imaginary circle $4.25^{\circ}$ from fixation, with locations at $0^{\circ}$ (top), $45^{\circ}$ (top right), $90^{\circ}$ (right), $135^{\circ}$ (bottom right), $180^{\circ}$ (bottom), $225^{\circ}$ (bottom left), $270^{\circ}$ (left), and $315^{\circ}$ (top left). Segments were tailored with a font editor to contain four rows of pixels rather than the two rows contained by an unedited forward slash, or the three contained by an unedited backslash. The forward slash was slanted approximately $50^{\circ}$ forward from upright, whereas the backslash was slanted approximately $50^{\circ}$ backward from upright. When two segments appeared in the display, they were on opposite sides of the imaginary circle upon whose perimeter they lay. When four segments appeared, they were spaced equidistant around this perimeter, one at every other possible location. All segments were presented at normal brightness.

Procedure. Each participant served in a single session of less than $1 \mathrm{~h}$ and received 240 criterion exposures, with two, four, and eight line segments appearing for 80 trials each. For half of each of these 80 trials, the target (backslash) was present, appearing five times at each possible location. The criterion trials were preceded by 20 practice ones. Right-handed participants pressed the " $\mathrm{j}$ " key with the index finger of the right hand as quickly as possible after display onset to indicate that the target was present, or the " $f$ " key with the index finger of the left hand to indicate that the target was absent. Key assignments were reversed for lefthanded participants. At the beginning of each trial, the backslash appeared as a reminder of the target orientation for $1 \mathrm{sec}$. The participant then gazed at the fixation dot, which appeared for $500 \mathrm{msec}$ in the center of the screen. The line segments then appeared simultaneously, and the participant responded as rapidly as possible with the appropriate hand. If the response was correct, a message indicating the participant's response time appeared for $1 \mathrm{sec}$, along with the word GOOD if time was less than $500 \mathrm{msec}$, the word FAIR if the time was 500-999 msec, or the words roo SLOW if the time was $1 \mathrm{sec}$ or greater. If the response was in error the computer beeped and the words OOPS! WRONG RESPONSE appeared, with no response time indicated. Both the trial on which the error was made and the next trial were rerun later in the session, appearing on some randomly chosen trial among the remaining exposures. All orders were completely randomized for each participant; that is, display sizes were intermixed in a random fashion.

\section{Results}

The first analysis was an analysis of variance (ANOVA) of the target present/absent response times (in milliseconds) for each number of segments in the display. Targetabsent responses $(M=632.47, S D=128.65)$ were significantly slower than target-present responses $(M=$ $587.70, S D=125.03)\left[F(1,9)=15.70, M S_{\mathrm{e}}=1,914.48\right.$, $p<.005]$. Response time actually declined as number of segments in the display increased from two segments $(M=635.45, S D=124.52)$ to four segments $(M=$ $607.45, S D=137.16)$ to eight segments $(M=587.35$, $S D=122.52)\left[F(2,18)=7.51, M S_{\mathrm{e}}=155.01, p<.005\right]$. The interaction between target present/absent and number of segments in the display was not significant $(F<1)$.

The second ANOVA was of location for each number of segments in the display for target-present trials. The means are plotted in Figure 2. The data are rather noisy, since there were only five target-present trials per data point per participant (since four versus eight segments produced no significant interaction with location-see below - their means are averaged for clarity). The main effect of location was significant $\left[F(7,63)=4.13, M S_{\mathrm{e}}=\right.$ $6,135.20, p<.001]$, as was the main effect of number of segments in the display $\left[F(2,18)=4.71, M S_{\mathrm{e}}=6,180.40\right.$, $p<.025]$, and also the interaction between these variables $\left[F(14,126)=3.13, M S_{\mathrm{e}}=5,919.20, p<.001\right]$.

Additional analyses were conducted in search of the source of the significant interaction. Analyses of the data with four versus eight segments in the display yielded a significant main effect of location $[F(7,63)=7.79$, $\left.M S_{\mathrm{e}}=5,059.00, p<.001\right]$, but no other significant effects ( $p=.244$ for the interaction). An analysis of the data comparing the means across four and eight seg-

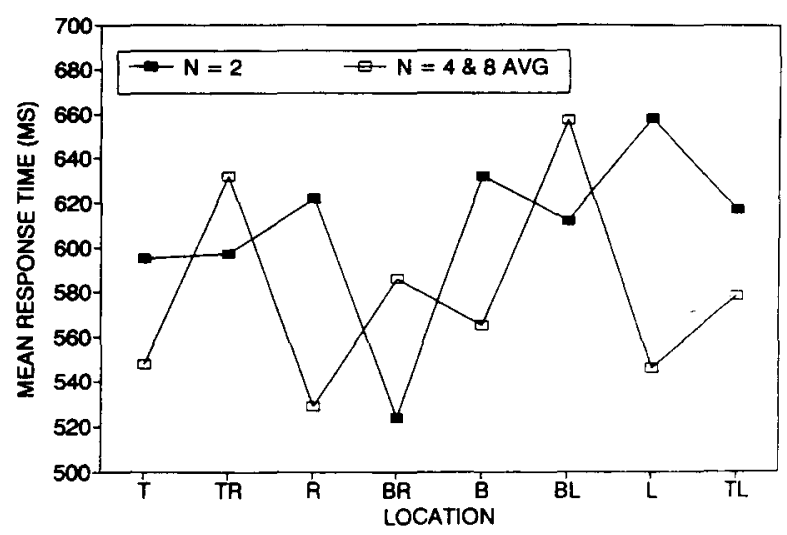

Figure 2. Mean response times for location by number of line segments on target-present trials in Experiment 1. 
Table 1

Mean Proportion of Responses in Error at Each Location on Target-Present Trials in Experiment 1

\begin{tabular}{ccccccccc}
\hline & \multicolumn{8}{c}{ Location } \\
\cline { 2 - 9 } & T & TR & R & BR & B & BL & L & TL \\
\hline$M$ & .040 & .147 & .033 & .040 & .113 & .187 & .147 & .107 \\
SD & .034 & .108 & .035 & .064 & .141 & .241 & .172 & .110 \\
\hline
\end{tabular}

ments with the data with two segments in the display revealed a significant interaction $[F(7,63)=4.73$, $\left.M S_{\mathrm{e}}=4,649.30, p<.001\right]$. The data in Figure 2 suggest that this interaction is at least partially due to longer response times when the backslash was at the top right or bottom left location. Accordingly, an analysis of the data with four versus eight segments, but those locations excluded, produced no significant effect of location $(p>$ $.05)$.

An analysis of errors at each location with each number of segments and the target present was conducted. Means for the only significant effect, that of location $\left[F(7,63)=2.63, M S_{\mathrm{e}}=.97, p<.02\right]$, appear in Table 1 . It is apparent that errors were most frequent when the target was at the bottom left, with top right tied with left for being the location at which errors were the second most frequent.

\section{Discussion}

Average reaction times did not increase, and in fact decreased significantly, as more background segments were added to the array. The unique segment therefore did pop out, and apparently adding more background segments (and thus making the systematic arrangement of the segments more apparent) made it pop out more strongly.

Longest response times and most frequent errors were produced when the unique slash appeared in a location that would place it at the end of the directional flow. This occurred with seven and three background segments in the display, but, of course, not with only one. By inference, three background segments were enough to produce the directional flow necessary to make the unique segment difficult to detect if it appeared at the end of the flow in the four-segment displays. Note that the four segments were spaced one every $90^{\circ}$ around the perimeter of an imaginary circle. Similar spacing may be necessary for so few segments to produce a directional flow (see Moraglia, 1989, p. 270, for a report of failure to find global organization from three segments spaced differently; and see Experiment 2 below, in which only three segments were used with different spacing).

\section{EXPERIMENT 2}

In the present experiment, line segments again were presented, but this time as precue displays. One segment was unique in its orientation relative to two other identically oriented ones and served as a precue that could be found through parallel processing. However, the unique line segment in conjunction with the segment appearing to each side form patterns that differ with their location in a circular display of line segments as shown in Figure 1 . When the unique segment falls at the end of the directional flow produced by the other segments, the local configuration is similar to three sides of a box (this can be seen in Examples A and C in Figure 1). When the unique segment falls at other locations within the directional flow, the local configuration does not have this appearance (see Examples B and D in Figure 1). Thus, with all segments presented, it would be unclear whether the effect of the unique segment falling at the end of the flow produced by the background segments is due to the direction of the flow or instead is attributable to this local configuration difference. ${ }^{1}$ To rule out the latter possibility, the five segments across the display from the unique one were not presented, leaving only three segments: the unique segment and the segment on each side of it. The unique segment always was a slash (rather than a backslash as in Experiment 1), and the other two segments always were backslashes. If all segments were present, the directional flow produced by the seven identical segments would be at the top left and bottom right, and accuracy of identifying the target characters at those locations should be lower than when it is at other locations. With only three segments in the precuing display, the targets at the top left and bottom right should not be identified significantly less accurately than those at other locations, because a single segment to each side of the unique one should not produce a directional flow.

\section{Method}

Participants. Ten participants served in fulfillment of an outside-of-class activities option in an introductory psychology course. Each reported normal or corrected-to-normal acuity.

Apparatus. The apparatus was that used in the preceding experiment. Eye movement was monitored continuously by the experimenter with a tripod-mounted box camera connected to a television set. Eye movement was detected on less than $1 \%$ of all exposures, and therefore probably had a negligible effect on error patterns.

Stimuli. All stimuli were presented at normal brightness. Each precuing display contained a unique segment, which was a slash, flanked to either side by a backslash. These three segments were displayed in an arc at the locations of three adjacent segments as shown in Figure 1. The target display contained eight circles with gaps, with the position of the gap in each circle being up, down, left, or right. Complete circles subtended a visual angle of approximately $.8^{\circ}$. One circle with a gap appeared every $45^{\circ}$, or equally spaced around the circumference of an imaginary circle $5.25^{\circ}$ from fixation, with locations at $0^{\circ}$ (top), $45^{\circ}$ (top right), $90^{\circ}$ (right), $135^{\circ}$ (bottom right), $180^{\circ}$ (bottom), $225^{\circ}$ (bottom left), $270^{\circ}$ (left), and $315^{\circ}$ (top left). A postexposure mask, present at each of the eight possible target locations, followed the outline of a complete circle.

Experimental Design. The precue indicated each of the eight locations equally often. The gap in the precued circle was equally likely to be in each of the four positions (positions of the gaps in the uncued circles were selected at random). The interval between the offset of the precuing display and the onset of the target display (interstimulus interval, or ISI) was $0,100,200,400,600$, or $800 \mathrm{msec}$. Thus the factorial combination of 2 repetitions $\times 8$ locations $\times 4$ gap positions $\times 6$ ISIs produced 384 trials per participant, with variable combinations presented in a different random order to each participant. 
Procedure. Each participant served in a single session of approximately $1 \mathrm{~h}$. At the beginning of each trial, the slash appeared as a reminder for $1 \mathrm{sec}$. The participant then gazed at the fixation dot, which appeared for $500 \mathrm{msec}$ in the center of the screen. The three line segments then appeared simultaneously for $33 \mathrm{msec}$. The ISI followed, with the target display then appearing for $67 \mathrm{msec}$, followed by the mask. The participant pressed one of the four arrow keys on the numeric keypad to indicate the position of the gap in the circle in the precued location. A "happy face" then appeared if the response was correct, or a minus sign if it was incorrect, for $1 \mathrm{sec}$. The next trial began after an intertrial interval of approximately $2 \mathrm{sec}$. The participant could pause at any time, merely by withholding the response until ready. To ensure that the participant kept his/her eyes at the correct distance from the screen and fixated on its center, a chinrest with head restraint was used and the eyes were monitored continuously on the closed-circuit television set. If an eye movement was detected immediately before, during, or immediately after the exposure, the participant was admonished by the experimenter.

\section{Results}

An ANOVA of mean proportion of responses correct revealed a significant effect of ISI (ISI $=0, .339 ;$ ISI $=$ $100, .512 ;$ ISI $=200, .491 ;$ ISI $=400, .550 ;$ ISI $=600$, $.600 ;$ ISI $=800, .617)\left[F(5,45)=13.86, M S_{\mathrm{e}}=.0581\right.$, $p<.001]$. The main effect of location, means for which appear in Table 2, also was significant $[F(7,63)=5.26$, $\left.M S_{\mathrm{e}}=.0357, p<.001\right]$, although the interaction between the two variables was not significant $(F<1.0)$.

Tukey (HSD) post hoc comparisons showed that accuracy when the cue was at the bottom left was significantly poorer than when it was at the left, top left, top right, or right. This test also revealed that accuracy when the cue was at the bottom right was significantly poorer than when it was at the left or right. Finally, when the cue was at the bottom, accuracy was significantly poorer than when it was at the right. No other difference was significant.

\section{Discussion}

Although the unique segment was flanked to each side by a background segment, so that a local configuration difference was produced that was identical to that which would be present if the unique segment were at the end of the directional flow produced when all seven background segments were present, target identification accuracy was not poorest at the top left and bottom right. Although accuracy at the bottom right was significantly poorer than at the left or right, accuracy at the bottom left was significantly poorer than at four other locations, and accuracy at the bottom was significantly poorer than at one other location. This indicates that accuracy for lo-

Table 2

Mean Proportion of Responses Correct at Each Location in Experiment 2

\begin{tabular}{lcccccccc}
\hline & \multicolumn{7}{c}{ Location } \\
\cline { 2 - 9 } & $\mathrm{T}$ & $\mathrm{TR}$ & $\mathrm{R}$ & $\mathrm{BR}$ & $\mathrm{B}$ & $\mathrm{BL}$ & $\mathrm{L}$ & $\mathrm{TL}$ \\
\hline $\mathrm{M}$ & .519 & .550 & .604 & .454 & .489 & .435 & .554 & .540 \\
$S D$ & .197 & .191 & .138 & .206 & .207 & .154 & .172 & .179 \\
\hline
\end{tabular}

Note-The critical difference for means is .097 . cations along the bottom of the display was poor in general. Moreover, accuracy at the top left was significantly higher than at the bottom left, and did not differ significantly from accuracy at any other location.

With the assurance provided by the present experiment that the expected location effects were not forthcoming from local configuration differences, the following experiment was conducted with line segments in various orientations used as precues.

\section{EXPERIMENT 3}

In the present experiment, eight line segments were present in each precue display. One segment was unique in its orientation relative to the other identically oriented ones and served as a precue that could be found through parallel processing. To ensure the generality of the effect, four groups of participants were each exposed to a different combination of line segment orientations. In addition, a fifth group received as a precue an arrow appearing at fixation, and a sixth group received a single line segment appearing alone in the visual field to serve as a precue.

As in a typical precuing experiment, the target character appeared in the precued location among other nontarget characters appearing in locations that were not precued on that particular trial. The precue--target delay (ISI) was varied to compare the time course of attention build-up with line segments of the various orientations in the various locations to each other and to that with the arrow at fixation and with a line segment appearing alone.

It was predicted that line segments whose orientation contrasted with that of background segments to place them at the end of the directional flow would not be found as rapidly (and thus would serve less well as precues) than line segments placed elsewhere. In general, it was expected that a unique line segment appearing among others would function as a symbolic precue in much the same way as an arrow appearing at fixation. That is, although the unique segment is detected through parallel processing, and thus stands out from its background, the expectation was that it would have to be interpreted and attention directed to its location. This prediction stems from findings reported by Chastain, Knorr, McAdams, Sulfridge, and Fleck (1994), who observed results suggesting that a red square appearing among green squares did not automatically summon attention. In contrast, it was expected that a line segment appearing alone in the precuing display would summon attention automatically to its location. Consequently, it was predicted that attention build-up would be faster with the line segment appearing alone, as comparisons between the effectiveness of symbolic and automatic precues have shown in the past (Cheal \& Lyon, 1991; Muller \& Rabbitt, 1989).

\section{Method}

Participants. Six groups of 10 participants per group served in fulfillment of an outside-of-class activities option in an introduc- 
tory psychology course. Each reported normal or corrected-tonormal acuity.

Apparatus. The apparatus was that used in the preceding experiment. Eye movement was monitored continuously by the experimenter with a tripod-mounted box camera connected to a television set. Eye movement was detected on less than $1 \%$ of all exposures to each group, and therefore probably had little effect on error patterns.

Stimuli. All stimuli were presented at normal brightness. For all but two groups of participants, a display containing multiple line segments was used to provide a precue for the target display that followed. The precue display was arranged identically to the displays in the preceding experiment. All eight possible locations always contained a line segment.

For Group A, each segment was a slanted line that was used in Experiment 1, with the precue being a backslash, and the background slashes being forward slashes.

For Group B, the segments were identical to those for Group A. However, the precue was the forward slash, and the background slashes were backslashes.

For Group C, the precue was a horizontal line, one character space in width and four pixels in height. The background segments were vertical lines, each 11 pixels high and 2 pixels wide.

For Group D, the segments were the same as for Group C. However, the precue was the vertical segment and the background segments were horizontal lines.

Group $E$ received an arrow at fixation (at the center of the display), approximately $1^{\circ}$ long and $.5^{\circ}$ wide, pointing toward the location where the upcoming target character would appear.

Group F received a single line segment (forward slash) as a precue on an otherwise empty field. It appeared at the same locations as the line segment precues for the other groups, and was the same segment used as a precue by Group B.

The target display contained eight small circles with gaps, with the position of the gap in each circle being up, down, left, or right. Complete circles subtended a visual angle of approximately.$^{\circ}$. One circle with a gap appeared every $45^{\circ}$, or equally spaced around the circumference of an imaginary circle $5.25^{\circ}$ from fixation, with locations at $0^{\circ}$ (top), $45^{\circ}$ (top right), $90^{\circ}$ (right), $135^{\circ}$ (bottom right), $180^{\circ}$ (bottom), $225^{\circ}$ (bottom left), $270^{\circ}$ (left), and $315^{\circ}$ (top left), with each of these immediately outside the corresponding precue location. A postexposure mask, present at each of the target locations, followed the outline of a complete circle.

Experimental Design. The design was similar to that in the preceding experiment. The factorial combination of 3 repetitions $\times 8$ locations $\times 4$ gap positions $\times 6$ ISIs produced 576 trials

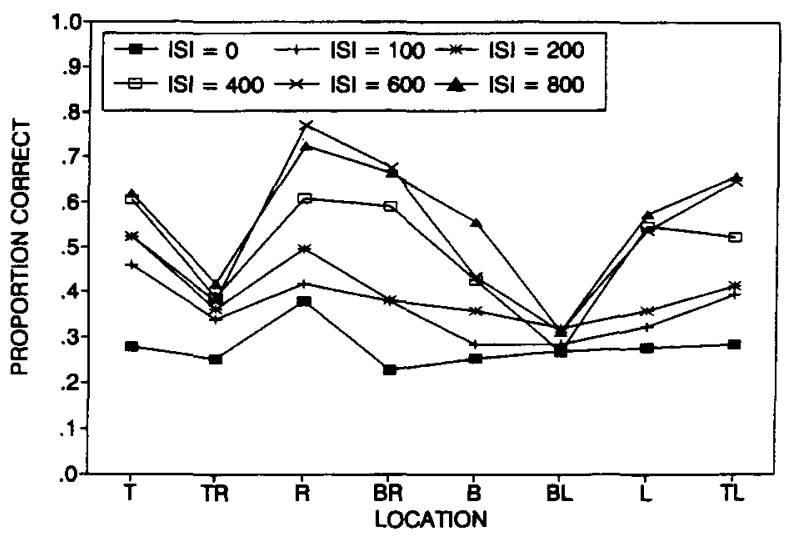

Figure 3. Mean proportion of responses correct for each ISI and location for Group $A$ (who received the backslash among slashes) in Experiment 3.
Table 3

Mean Proportion of Responses Correct at Each Location for Each Group in Experiment 3

\begin{tabular}{lcccccccc}
\hline & \multicolumn{7}{c}{ Location } \\
\cline { 2 - 9 } Group & $\mathrm{T}$ & $\mathrm{TR}$ & $\mathrm{R}$ & $\mathrm{BR}$ & $\mathrm{B}$ & $\mathrm{BL}$ & $\mathrm{L}$ & $\mathrm{TL}$ \\
\hline $\mathrm{A}(.124)$ & & & & & & & & \\
$M$ & .506 & .355 & .565 & .486 & .401 & .293 & .435 & .486 \\
$S D$ & .128 & .114 & .115 & .077 & .118 & .070 & .117 & .102 \\
$\mathrm{~B}(.130)$ & & & & & & & & \\
$M$ & .459 & .597 & .564 & .324 & .392 & .452 & .491 & .356 \\
$S D$ & .105 & .110 & .148 & .074 & .098 & .135 & .075 & .072 \\
$\mathrm{C}(.130)$ & & & & & & & & \\
$M$ & .411 & .556 & .621 & .520 & .387 & .439 & .556 & .544 \\
$S D$ & .084 & .089 & .063 & .122 & .085 & .106 & .080 & .079 \\
$\mathrm{D}(.137)$ & & & & & & & & \\
$M$ & .513 & .597 & .532 & .503 & .493 & .446 & .492 & .580 \\
$S D$ & .105 & .107 & .127 & .070 & .082 & .070 & .088 & .094 \\
$\mathrm{E}(.128)$ & & & & & & & & \\
$M$ & .423 & .544 & .521 & .501 & .460 & .398 & .464 & .432 \\
$S D$ & .146 & .099 & .168 & .102 & .143 & .137 & .142 & .134 \\
$\mathrm{~F}(.122)$ & & & & & & & & \\
$M$ & .566 & .659 & .675 & .581 & .448 & .413 & .606 & .532 \\
$S D$ & .063 & .117 & .104 & .101 & .090 & .054 & .119 & .066 \\
\hline
\end{tabular}

Note-The critical difference for means in each row is indicated beside the group's letter designation above that row.

per participant, with variable combinations presented in a different random order to each participant.

Procedure. Each participant served in a single session of approximately $1 \mathrm{~h}$. At the beginning of each trial, the line segment in the proper precue orientation appeared as a reminder for $1 \mathrm{sec}$ to Groups A, B, C, D, and F. The participant then gazed at the fixation dot which appeared for $500 \mathrm{msec}$ in the center of the screen. The eight line segments (for Groups A, B, C, and D) then appeared simultaneously for $33 \mathrm{msec}$, as did the single line segment for Group $F$ and the arrow at fixation for Group E. The ISI followed, with the target display then appearing for $67 \mathrm{msec}$, followed by the mask. The participant pressed one of the four arrow keys on the numeric keypad to indicate the position of the gap in the circle in the precued location, and feedback was provided as in the preceding experiment.

\section{Results}

An ANOVA was conducted on mean proportion of responses correct for targets appearing at each location and ISI for each participant within each group. Analyses for the groups will be presented separately.

Group A. Group A received the backslash precue among forward slashes. The means are plotted in Figure 3. The effects of location $\left[F(7,63)=9.94, M S_{\mathrm{e}}=\right.$ $.047, p<.001]$ and ISI $\left[F(5,45)=33.10, M S_{\mathrm{e}}=.032\right.$, $p<.001$ ] were significant, as was the location $\times$ ISI interaction $\left[F(35,315)=2.54, M S_{\mathrm{e}}=.017, p<.001\right]$. Location means appear in Table 3 .

A segment at the end of the directional flow was at the top right or bottom left, and numerically means for these two locations were the lowest. According to Tukey (HSD) analysis, means that differ by more than .124 are significantly different. Therefore, performance was significantly poorer with the precue at bottom left than with the precue at every other location except top right and bottom, and performance with the precue at top right was significantly poorer than that with the precue at every re- 
maining location except two: bottom and left. Accordingly, performance with the precue at the bottom was significantly poorer than that with the precue at the right. No other difference was significant.

Inspection of Figure 3 suggests that the significant interaction between location and ISI is due to compressed ISI effects at the top right and bottom left. Separate analysis showed that the effect of ISI was not significant at either the top right $[F(5,45)=1.43, p>.05]$ or bottom left $(F<1.0)$. The effect of ISI was significant at all other locations.

Group B. Group B received the forward slash precue among backslashes. A graph of the means appears as Figure 4. The effects of location $\left[F(7,63)=10.76, M S_{\mathrm{e}}=\right.$ $.051, p<.001]$ and ISI $\left[F(5,45)=26.15, M S_{\mathrm{e}}=.034\right.$, $p<.001]$ were significant, as was the location $\times$ ISI interaction $\left[F(35,315)=1.75, M S_{\mathrm{e}}=.021, p<.01\right]$. The location means appear in Table 3.

A segment at the end of the directional flow was at the top left or bottom right, and numerically means for these two locations were the lowest. Tukey (HSD) analysis showed the critical difference to be .130 . Therefore, performance with the precue at the bottom right was significantly poorer than that with the precue at every other location except top left, bottom, and bottom left. Performance with the precue at the top left was significantly poorer than that with the precue at every remaining location except bottom, bottom left, and top. Performance with the precue at the bottom was significantly poorer than with the precue at the right or top right. Performance with the precue at the bottom left or top was significantly poorer than that with the precue at top right. No other difference was significant.

Inspection of Figure 3 suggests that the significant interaction between location and ISI is due to compressed ISI effects at the top left and bottom right. Separate analysis showed that the effect of ISI was significant at the top left $[F(5,45)=2.97, p<.025]$, but not at the bottom right $[F(5,45)=1.15, p>.05]$. The effect of ISI was significant at all other locations.

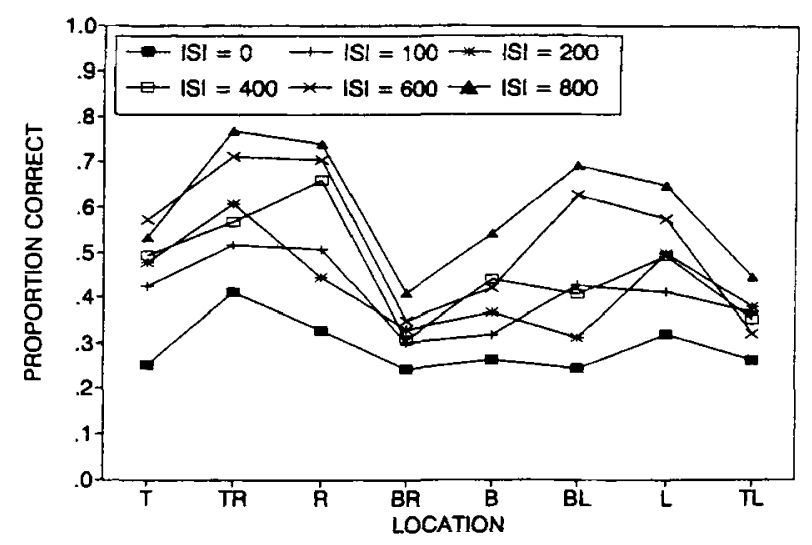

Figure 4. Mean proportion of responses correct for each ISI and location for Group $B$ (who received the slash among backslashes) in Experiment 3.

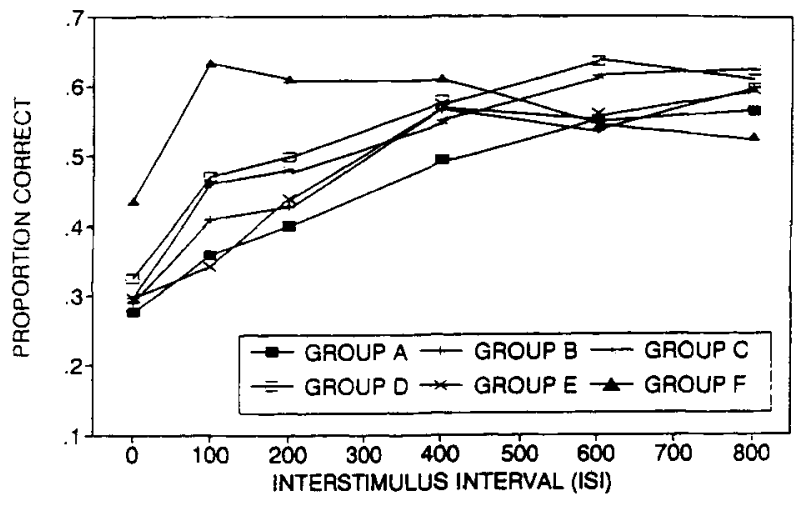

Figure 5. Mean proportion of responses correct for each ISI for each group in Experiment 3 (Group A, backslash among slashes; Group B, slash among backslashes; Group C, horizontal among verticals; Group D, vertical among horizontals; Group E, arrow at fixation; Group F, single slash).

Group C. Group C received the horizontal line segment precue among vertical line segments. The means for ISIs appear in Figure 5, whereas those for location appear in Table 3. Both main effects were significant: location $\left[F(7,63)=7.90, M S_{\mathrm{e}}=.052, p<.001\right]$ and ISI $\left[F(5,45)=34.45, M S_{\mathrm{e}}=.034, p<.001\right]$. The interaction was not significant $[F(35,315)=1.10, p>.05]$.

A segment at the end of the directional flow was at the top or bottom, and numerically means for these two locations were the lowest. Tukey (HSD) analysis again showed the critical difference to be .130. Performance with the precue at the bottom was significantly poorer than performance with the precue at all other locations except the top and bottom left. Likewise, performance with the precue at the top was significantly poorer than performance with the precue at all remaining locations except the bottom left and bottom right. Finally, performance with the precue at the bottom left was significantly poorer than that with it at right. No other difference was significant.

Group D. Group D received the vertical line segment precue among horizontal line segments. The means for the ISIs appear in Figure 5, whereas the means for location appear in Table 3. Both main effects were significant: location $\left[F(7,63)=2.55, M S_{\mathrm{e}}=.057, p<.025\right]$ and ISI $\left[F(5,45)=32.97, M S_{\mathrm{e}}=.032, p<.001\right]$. The interaction was not significant $[F(35,315)=.93, p>.05]$.

A segment at the end of the directional flow was at the left or right, although numerically, the means for these two locations were not the lowest. Tukey (HSD) analysis showed the critical difference to be .137. Performance with the precue at the bottom left was significantly poorer than performance with the precue at the top right. No other difference was significant.

Group E. Group E received the arrow at fixation as a precue. The means for ISI appear in Figure 5, whereas those for location appear in Table 3. Both main effects were significant: location $\left[F(7,63)=2.55, M S_{\mathrm{e}}=.050\right.$, $p<.01]$ and ISI $\left[F(5,45)=23.46, M S_{\mathrm{e}}=.055, p<.001\right]$. 
The interaction was not significant $[F(35,315)=1.40$, $p>.05]$.

Tukey (HSD) analysis showed the critical difference to be .128 . Performance with the precue pointing to the bottom left was significantly poorer than performance with the precue pointing to the top right. No other difference was significant.

Group F. Group F received the forward slash appearing alone in the precue field. Both main effects were significant: location $\left[F(7,63)=11.58, M S_{\mathrm{e}}=.045, p<\right.$ $.001]$ and ISI $\left[F(5,45)=16.98, M S_{\mathrm{e}}=.026, p<.001\right]$. The interaction was not significant $[F(35,315)=1.05$, $p>$.05].

Tukey (HSD) analysis showed the critical difference to be .122. Performance with the precue at the bottom left was significantly poorer than that at any other location except the bottom and top left, and performance with the precue at the bottom was significantly poorer than performance at any other remaining location except the top left and top. Performance with the precue at the top left was significantly poorer than that with the precue at the top right or right. No other difference was significant.

Group B versus Experiment 2. Accuracy at the eight locations for Group B in the present experiment was compared with that in Experiment 2. Although in both experiments the slash was the precue, in Experiment 2 it was accompanied by only one backslash to each side. In that experiment, accuracy was not lowest at the top left and bottom right. ANOVA of the data of the two groups was performed. Means may be derived from Figure 6 for the significant main effect of location $[F(7,126)=$ $\left.13.14, M S_{\mathrm{e}}=.00727, p<.001\right]$ and the significant groups $\times$ location interaction $\left[F(7,126)=3.90, M S_{\mathrm{e}}=.00727\right.$, $p<.001]$. The main effect of groups was not significant $(p>.05)$.

Tukey (HSD) analysis showed the critical difference in the significant interaction to be .114. Only the difference in accuracy between the groups at the top left and bottom right was significant, with accuracy significantly poorer at those locations in the present experiment than in the preceding one. These are the locations that place

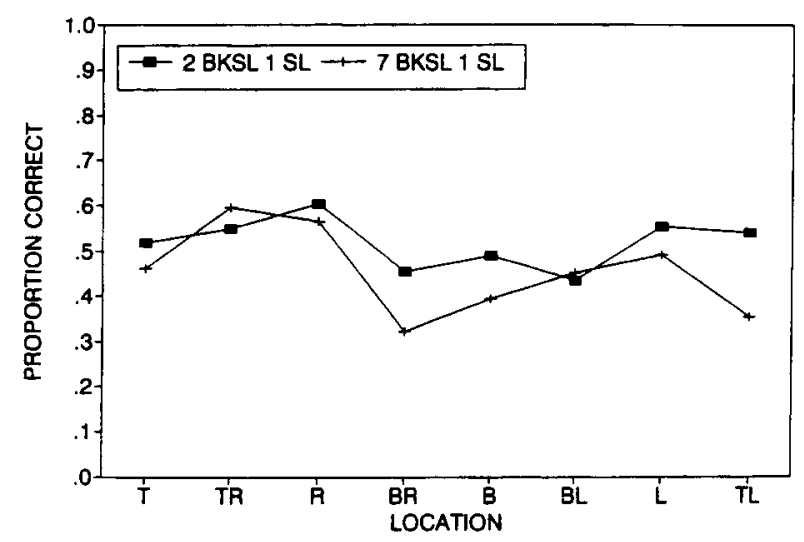

Figure 6. Mean proportion of responses correct for each location for Experiment 2 and Group $B$ in Experiment 3 (both groups of subjects received a slash among backslashes). the slash at the end of the directional flow created by the seven backslashes.

Difference in ISI effect for the groups. An ANOVA was conducted on the ISI data of all six groups. The means appear in Figure 5. The effects of groups $[F(5,54)=5.40$, $\left.M S_{\mathrm{e}}=.023, p<.001\right]$ and ISI $\left[F(5,270)=119.01, M S_{\mathrm{e}}=\right.$ $.005, p<.001]$ were significant, as was the groups $\times$ ISI interaction $\left[F(25,270)=5.61, M S_{\mathrm{e}}=.005, p<.001\right]$. Comparisons of trends across ISIs for the groups were conducted to determine the source of the significant interaction. Rather than assign weights assuming equal intervals between all consecutive pairs of ISIs, assignment was made to reflect the unequal intervals. The linear trend across ISIs differed significantly for the groups $[F(5,54)=$ $\left.10.98, M S_{\mathrm{e}}=.016, p<.001\right]$. Fisher's Protected LSD tests of all possible differences showed that the linear trend for Group $\mathrm{F}$ was significantly less pronounced than that for the other five groups, although no other difference was significant. The quadratic trend across ISIs, again with weights reflecting the unequal intervals, revealed no significant overall difference among the groups $[F(5,54)=$ $\left.1.63, M S_{\mathrm{e}}=.029, p>.05\right]$. An additional analysis showed that accuracy at ISI $=0$ did differ among the groups $\left[F(5,54)=5.66, M S_{\mathrm{e}}=.006, p<.001\right]$. However, when the data of Group $\mathrm{F}$ were omitted, accuracy at ISI $=0$ did not differ among the remaining groups $(F<1)$.

A final complete analysis was conducted on the data from Group B, who received the forward slash among backslashes as a precue, and Group F, who received the forward slash alone as a precue. The relevant means appear in Table 3. All main effects were significant, as was the interaction between groups and ISI (all $p \mathrm{~s}<.001$ ). However, the comparison of particular interest is the groups $\times$ location interaction, which also was found to be significant $\left[F(7,126)=4.76, M S_{\mathrm{e}}=.048, p<.001\right]$. Neither the interaction between location and ISI nor the three-way interaction among groups, location, and ISI, was significant (both $p s>.05$ ). If the critical locations at the end of the flow for Group B (top left and bottom right) are omitted for the two groups, the groups $\times$ location interaction no longer is significant $(F<1)$, nor is the main effect of location, nor does the groups $\times$ ISI $\times$ location interaction become significant $(p \mathrm{~s}>.05)$. Along with the results of Experiment 2, this shows that the location effect for Group B was not due to some local pattern formed by the line segment's being tangent to the target circle, but was due to the orientation contrast produced by the forward slash appearing among backslashes.

Additional simple comparisons were made to determine the point of asymptote for Groups A, B, C, D, and $E$, in comparison with that for Group F. For the first five groups, performance improvement continued through ISI $=600 \mathrm{msec}$ (performance difference between ISI = $400 \mathrm{msec}$ and ISI $=600 \mathrm{msec}$ was found to be significant, $p<.001$, with no significant groups $\times$ ISI interaction), whereas there was no significant difference between ISI $=600 \mathrm{msec}$ and ISI $=800 \mathrm{msec}$ (both the effect of ISI and the groups $\times$ ISI interaction $p s>.05$ ). For Group F, every participant showed improvement 
from ISI $=0$ to ISI $=100 \mathrm{msec}$, although there was no significant difference between performance at ISI = $100 \mathrm{msec}$ and ISI $=200 \mathrm{msec}$, or between performance at ISI $=200$ and ISI $=400$ (both $p \mathrm{~s}>.05$ ). Performance declined significantly between ISI $=400 \mathrm{msec}$ and ISI $=$ $600 \mathrm{msec}$ for this group $(p<.05)$. There was no significant additional decline between ISI $=600$ and ISI $=800$ $(p>.05)$.

\section{Discussion}

In accordance with predictions, the unique line segment tended to serve least well as a precue in locations where its orientation in contrast with that of the background segments placed it at the end of the directional flow. As judged from the presence of a significant location $\times$ ISI interaction, this was most apparent for Group A, who received the backslash precue among forward slashes, and Group B, who received the forward slash precue among backslashes. The absence of a significant ISI effect at top right or bottom left for Group A, or at bottom right for Group B, suggests that the unique segment often may not have been detected when it was at those locations. The location $\times$ ISI interaction was not significant for Group $C$ or $D$, both of whom received vertical and horizontal line segments. Because oblique line segments have been found less salient than vertical or horizontal segments by other researchers (Appelle, 1972; Matin \& Driver, 1979), an oblique segment may have been particularly difficult to see when it was at the end of the directional flow of background segments. A horizontal segment among verticals also appears to have been least visible when it was at the top or bottom, the end of the directional flow of vertical line segments, although the vertical segment among horizontals was not least visible when it was at the left or right. As is evident from Table 3, precues to the left and right tended to produce high performance overall. Schaller and Dziadosz (1975) found that accuracy of detecting a single vertical or horizontal bar embedded in one circle of a $5 \times 7$ array of circles declined with eccentricity more slowly to the left/right of fixation than to other directions. Thus retinal sensitivity factors may have worked against the effect of reduced visibility at the ends of the directional flow for Group D.

For Group E (who were shown the arrow at fixation as a precue) and Group F (who were shown the line segment alone as a precue), performance was poor for locations at the bottom and left of the display. Schaller and Dziadosz's (1975) results also correctly predict poor performance at the bottom; retinal sensitivity fell off most quickly at locations below fixation in their study.

As is evident from the analysis of groups and ISI, and in accordance with predictions, the line segment appearing alone (Group F) produced the best performance at ISI $=0$. This may have occurred because the precue exposure duration was $33 \mathrm{msec}$ and that of the target was $67 \mathrm{msec}$, and attention can be reallocated during the exposure of the precue and target. Group $F$ performance was at asymptote at 100,200 , and $400 \mathrm{msec}$; it then de- clined until a new, lower plateau was reached at around $600 \mathrm{msec}$. In contrast, for the other groups, performance improved until an ISI of $600 \mathrm{msec}$, but not between ISIs of 600 and $800 \mathrm{msec}$. Because performance was at asymptote for almost $300 \mathrm{msec}$ for Group F, but did not reach asymptote for Groups $\mathrm{A}-\mathrm{E}$ until nearly the end of the ISI range, interpreting the decline in performance for single element precues but not for other precue types at longer ISIs becomes problematic.

However, the difference in performance across ISIs for Group F versus the other groups, in conjunction with the similarity in this performance between Group E and Groups A-D, is consistent with the proposition that the single-element peripheral precue affects attention differently from the others. That is, a single shape appearing alone automatically elicits attention to its location, whereas a precue detected through visual search (even parallel search) is symbolic and must be interpreted so that attention voluntarily can be allocated to its location. In this way, a precue detected through visual search is similar to an arrow presented at fixation, which allows attention to be directed to the location it indicates (Cheal \& Lyon, 1991).

Group B received the slash among backslashes, and Group $F$ received the slash appearing alone. The comparison of the data of Groups $B$ and $F$ produced a significant groups $\times$ location interaction, indicating that the source of the location effects for Group B was not merely a relation between the slash and target such that the slash (or more precisely, its afterimage) was tangent to the target circle when it appeared at the top left and bottom right, but not at other locations. When the slash appeared alone, performance was poorer at the bottom or bottom left than at the top left, and performance at the bottom right was not significantly lower than performance at the right, top right, or left, the locations producing the highest performance means numerically. In addition, accuracy at the top left and bottom right for Group B was significantly poorer than accuracy at those locations in Experiment 2, in which the slash precue was flanked to each side by one backslash.

The comparison of location data for Groups B and F also emphasizes the importance of global versus local factors in interpreting effects related to the segment used as a precue, the slash. Moraglia (1989) stressed absolute position of a single element as critical. He found detection of a horizontal line segment to be poorest when it was presented at a location whose tangent to the circular display of segments also was horizontal. However, Nothdurft (1993b) stressed feature contrast rather than the nature of a single feature as crucial. The present findings support Nothdurft's emphasis of global over local factors as important in the detection of a single feature such as a line segment.

\section{GENERAL DISCUSSION}

The three experiments just described provide evidence for the proposition that, with brief presentations, a 
uniquely oriented line segment appearing at the end of the directional flow produced by sparsely distributed background segments is detected more slowly than when the uniquely oriented segment appears elsewhere. The concept of detection through parallel processing from orientation contrast (Nothdurft, 1991) thus needs to be qualified to include consideration of relative location of the contrasting element. In arrays of lines, the speed with which a segment at a different orientation from identically oriented background segments is detected depends on the location of the target relative to the directional flow. A plausible interpretation of the present findings is that a segment at either end of the flow serves merely as a boundary that provides no information; even without this segment, it is apparent that the flow has terminated.

Density of the line segments probably is important. An array of eight line segments arranged in a circular pattern, with distance between segments of approximately $3^{\circ}$ (as in the present experiments) provides a fairly sparse distribution. An even more sparse distribution was present in Experiment 1, with four segments, one every $90^{\circ}$, which nevertheless produced the directional-flow contrast effect. H. C. Nothdurft (personal communication, January 13,1994 ) observed no pronounced dependence between single-target-segment location relative to the global distribution of segments and target orientation in his study (Nothdurft, 1991) when the segments were more densely distributed. Further research is needed in order to determine the effect of distribution density on relative location effects from orientation contrast.

The speed of detection through parallel processing being dependent upon orientation and relative location has implications for what would need to be included in a general model to enhance our understanding of attentional elicitation. Attentional elicitation arguably is based on a priority map that tags a single feature in the visual field within a preattentive visual representation (Yantis \& Hillstrom, 1994). The present results make clear the fact that the location of the unique feature relative to other identical features can be critical in the speed with which the unique feature is tagged, even when tagging the feature is task relevant (Bacon \& Egeth, 1994).

In general, a unique line segment with an orientation that contrasted well with background segments was detected through parallel processing, but nevertheless seemed to serve as a symbolic cue that allowed participants to direct attention rather than as a cue that automatically summoned attention. The pattern of performance across ISIs with the multiple-element precues was similar to that with the precue in the form of an arrow at fixation. The unique line segment was presented immediately before each trial as a reminder to the participant, and therefore participants should have been sensitive to the attribute (line orientation) designated to control attention. As gauged from performance across ISIs, and especially accuracy at ISI $=0$, a single-element precue in the form of a line segment appearing alone elicits attention in a way that detection of a short line segment among other elements through parallel processing does not.
An interesting extension of the present findings would be to compare postasymptotic precue-target delays, using a range of delays that allows asymptotic performance to be maintained for intervals that are equal for single- and multiple-element precues. Either the range of delays could be extended from that in the current study, or multiple-element precues could be used that allow attention to reach asymptote more rapidly. Color or brightness differences could be more salient than orientation differences (Nothdurft, 1993a, 1993b).

Another possible follow-up would be to vary the validity of the precue, using both multiple-element and single-element precue displays. Following the logic of such researchers as Yantis and Jonides (1990), Theeuwes (1991), and Folk, Remington, and Johnston (1992), if attention automatically is drawn, performance should be better on valid trials, when the precue correctly indicates the target's location, whatever the overall validity. However, if attention must be directed actively, performance will be better on valid trials only when overall validity is high. If overall validity is at chance, subjects will not actively use the precue, and performance will be no better on valid than on invalid trials. From the results of Experiment 3 , one might predict that the multiple-element precue would require that attention be directed actively, whereas the single-element precue would draw attention automatically to its location. Such an experiment has recently been conducted in this laboratory, with results as predicted (Chastain et al., 1995).

More generally, the value of attentional elicitation has been related by Cavanagh, Arguin, and Treisman (1990) to the way the visual system makes an early determination of surfaces. A disparate feature may signal a discontinuity reflecting a different surface, and this can be distinguished preattentively. The present results suggest, however, that if the disparate feature falls at the end of the flow of a group of sparsely but regularly distributed and identically oriented features, no implication is present for a surface break in the area containing the elements. The disparate feature provides no additional information beyond that from the absence of additional features oriented in the direction of the flow, and thus the disparate feature is not salient. Boundary conditions have yet to be established for this directional-flow contrast effect, although the present results invite further research. Density, line length, orientation relations, and other features of line-segment displays could be varied to provide a better understanding of the phenomenon.

\section{REFERENCES}

Appelle, S. (1972). Perception and discrimination as a function of stimulus orientation: The "oblique" effect in man and animals. Psychological Bulletin, 78, 266-278.

BACON, W. F., \& EGETH, H. E. (1994). Overriding stimulus-driven attentional capture. Perception \& Psychophysics, 55, 485-496.

Cavanagh, P., Arguin, M., \& Treisman, A. (1990). Effect of surface medium on visual search for orientation and size features. Journal of Experimental Psychology: Human Perception \& Performance, 16, 479-491.

Chastain, G., Davis, R., Tipton, M., Hills, J., Hood, J., \& Fredde, M. 
(1995, November). Is focal attention automatically drawn by popout? Paper presented at the meeting of the Psychonomic Society, Los Angeles.

Chastain, G., Knorr, J., McAdams, J., Sulfridge, J., \& Fleck, J. (1994, November). Attentional effects from abrupt-onset-singleton and pop-out precues. Paper presented at the meeting of the Psychonomic Society, St. Louis.

ChEAL, M., \& LYON, D. (1989). Attention effects on form discrimination at different eccentricities. Quarterly Journal of Experimental Psychology, 41A, 719-746.

ChEAL, M., \& LyON, D. (1991). Central and peripheral precuing of forced-choice discrimination. Quarterly Journal of Experimental Psychology, 43A, 859-880.

Fol., C. L., Remington, R. W., \& Johnston, J.C. (1992). Involuntary covert orienting is contingent on attentional control settings. Journal of Experimental Psychology: Human Perception \& Performance, 18, 1030-1044.

HeL-Or, Y., \& ZuCKER, S. W. (1989). Texture fields and texture flows: Sensitivity to differences. Spatial Vision, 4, 131-139.

JONIDES, J., \& YANTIS, S. (1988). Uniqueness of abrupt visual onset in capturing attention. Perception \& Psychophysics, 43, 346-354.

LYON, D. R. (1990). Large and rapid improvement in form discrimination accuracy following a location precue. Acta Psychologica, 73, 69-82.

Matin, E., \& Driver, A. (1979). Acuity for orientation measured with a sequential recognition task and signal detection methods. Perception \& Psychophysics, 25, 161-168.

MoRaglia, G. (1989). Display organization and the detection of horizontal line segments. Perception \& Psychophysics, 45, 265-272.

MulleR, J. J., \& RabBitT, P. M. A. (1989). Reflexive and voluntary orienting of visual attention: Time course of activation and resistance to interruption. Journal of Experimental Psychology: Human Perception \& Performance, 15, 315-330.

NothduRFT, H. C. (1991). Texture segregation and pop-out from orientation contrast. Vision Research, 31, 1073-1078.

NothduRFT, H. C. (1993a). The conspicuousness of orientation and motion contrast. Spatial Vision, 7, 341-363.

Nothdurft, H. C. (1993b). The role of features in preattentive vision: Comparison of orientation, motion, and color cues. Vision Research, 33, 1937-1958.
Remington, R. W., Johnston, J. C., \& Yantis, S. (1992). Involuntary attentional capture by abrupt onsets. Perception \& Psychophysics, 51, 279-290.

SAGI, D., \& Julesz, B. (1985). "Where" and "what" in vision. Science, 228, $1217-1219$.

SCHALlER, J. M., \& DzIADosz, G. M. (1975). Individual differences in adult foveal asymmetries. Journal of Experimental Psychology: Human Perception \& Performance, 1, 353-365.

TheEuWEs, J. (1991). Exogenous and endogenous control of attention: The effect of visual onsets and offsets. Perception \& Psychophysics, 49, 83-90.

Treisman, A. (1977). Focused attention in the perception and retrieval of multidimensional stimuli. Perception \& Psychophysics, 22, 1-11.

Treisman, A. (1986). Features and objects in visual processing. Scientific American, 255(5), 114B-125.

Treisman, A., \& Gormican, S. (1988). Feature analysis in early vision: Evidence from search asymmetries. Psychological Review, 95, 15-48.

Wolfe, J. M., Friedman-Hill, S. R., Stewart, M. I., \& O'Connell, K. M. (1992). The role of categorization in visual search for orientation. Journal of Experimental Psychology: Human Perception \& Performance, 18, 34-49.

YANTIS, S., \& Hillstrom, A. P. (1994). Stimulus-driven attentional capture: Evidence from equiluminant visual objects. Journal of Experimental Psychology: Human Perception \& Performance, 20, 95 107.

YANTIS, S., \& JoNIDES, J. (1984). Abrupt onsets and selective attention: Evidence from visual search. Journal of Experimental Psychology: Human Perception \& Performance, 10, 601-621.

YANTIS, S., \& Jonides, J. (1990). Abrupt visual onsets and selective attention: Voluntary versus automatic allocation. Journal of Experimental Psychology: Human Perception \& Performance, 16, 121-134.

\section{NOTE}

1. I would like to thank Chip Folk for suggesting this possibility.

(Manuscript received May 16, 1994; revision accepted for publication December $7,1995$. 